\title{
Ovarian Wilms Tumor
}

National Cancer Institute

\section{Source}

National Cancer Institute. Ovarian Wilms Tumor. NCI Thesaurus. Code C40443.

An embryonal neoplasm arising from the ovary with morphologic features resembling Wilms tumor of the kidney. It occurs during the reproductive age and may present as a rapidly growing adnexal mass. 